\title{
Power Control of High Penetration PV in Distribution Network
}

\author{
Saman Hosseini Hemati*, Ashkan Mohammadi \\ Electrical Engineering Department, Faculty of Engineering, Kermanshah Branch, Islamic Azad University, \\ Kermanshah, Iran \\ ${ }^{*}$ Corresponding author, e-mail: saman.h@live.com
}

\begin{abstract}
Photovoltaic energy is one of the fastest growing renewable energy sources in the worldand as the issue of energy security is becoming more and more important it could be a promising option. But as photovoltaic energy is becoming widespread and penetration level of photovoltaic power plants increase, issues rise in distribution networks. In this paper a power control scheme for a high penetration photovoltaic power plant in a radial distribution network will be presented. This control scheme includes an efficient Maximum Power Point Tracking (MPPT), DC link voltage control by managing power balance between the hysteresis controlled inverter and a boost converter. Another aspect of High Penetration PV (HPPV) which is overvoltage in Point of Common Coupling $(P C C)$ is also investigated and maximum allowable Penetration Level (PL) will be determined. Simulations have been done in Matlab/Simulink environment.
\end{abstract}

Keywords: distribution network, maximum power point tracking, photovoltaic, power control

Copyright $\odot 2015$ Institute of Advanced Engineering and Science. All rights reserved.

\section{Introduction}

Photovoltaic (PV) energy is one of the fastest growing renewable energy sources in the world. Currently there are several initiative projects which are targeted on developing and improving the key technology of enabling high renewable energy penetration in the electrical grid of future, such as the Intelligrid project of the Electric Power Research Institute (EPRI), the smart grid demonstration projects of the U.S. Department of Energy (DOE), the Galvin Perfect Power Initiative project, and others [1, 2].

The annual growth rate of photovoltaic energy is $25-35 \%$ over the last ten years and $156 \%$ and $85 \%$ annual growth rate in US only in 2012 and 2013 respectively. The markets for solar PV have undergone a dramatic shift in the last ten years. Prior to 2000 the primary market for PV was in off-grid applications, such as rural electrification, water pumping, and telecommunications. However, now most of the global market is for grid-connected applications where the power is fed into the electrical network. Furthermore, most of the new PV capacity has been installed in the distribution grid as distributed generation. As the use of solar PV continues to expand, concern about its potential impact on the stability and operation of the grid grow too. Utilities and power system operators are preparing for changes to integrate and manage more of this renewable electricity source in their systems.

The penetration level is defined as the ratio of nameplate PV power rating to the maximum load seen on the distribution feeder. The voltage rise issue has been reported as one of the concerns under high penetration of renewable Distributed Generations (DG) [3]. The reverse power flow caused by large amounts of DG may cause voltage rise to which distribution network operators control cannot effectively respond since the traditional grid has been planned to deliver power to the load at satisfactory voltage range [4].

Two major studies $[5,6]$ concentrated on distributed generators interfaced to utilities through inverters, and larger-scale system impacts and rotating distributed generation (DG), but still with several results on inverter-based DG. The first study [5] concluded that for DG penetration levels of $40 \%$, such that the system is heavily dependent on DGs to satisfy loads, voltage regulation can become a serious problem. The sudden loss of DGs, particularly as a result of false tripping during voltage or frequency events, can lead to unacceptably low voltages in portions of the system. During periods of low load but high generation and with certain distribution circuit configurations, the reverse power flow condition could cause 
malfunctions of the series voltage regulators. Again, voltage regulation becomes a problem. A voltage regulation function, implemented through reactive power control, would enable inverterbased DGs to be much more beneficial to the grid than they currently are. But this function would interfere with most anti-islanding schemes as they are presently implemented. Inverterbased DGs do not contribute significantly to fault currents, and thus did not adversely impact coordination strategies for fuses and circuit breakers. The study notes that the short-duration fault current contribution of small distributed inverter-based DGs is smaller than that of distributed induction machines. However, it also points out that this might not always be true if the DG is connected at a point where the utility series impedance is unusually high. These conclusions may not remain valid if the voltage regulation controls suggested above are implemented.

Reference [4] proposes a method of reactive power injection which is not to control bus voltage but to guarantee that active power generation does not cause voltage rise. The advantage is that the voltage becomes independent of the generation and the distribution network operators can be kept to their traditional task of voltage regulation. However, as illustrated in the paper, the disadvantages are the higher On-Load Tap Changer (OLTC) stress and feeder loss. Another drawback is that this method requires information about the upstream feeder impedance resulting in a communicating need in case of feeder reconfiguration. Reference [7] also presents a method of reactive power control where inverters decide their output reactive power autonomously at first, and continuously modify them with exchanging information between each inverter.

The General Electric (GE) 2008 report [8] compares the performance with different penetration levels when using OLTC transformer, step voltage regulator (SVR) or PV inverter to regulate the distributed load voltage. The key conclusion from the report is that coordinated control of utility equipment and DG assets can be used to enhance the performance of distribution systems. In addition, a communication link established between service points (customer meter connections) and the utility equipment is helpful. The report investigates on the reactive power support from PV inverters. But as pointed out in the report, at present, the IEEE 1547 and UL 1741 only allow PV systems to operate at a unity power factor. However, it provides a promising method if the standard can be changed in the future.

In this paper, a grid connected high penetration PV is simulated and voltage rise issue and power control scheme are discussed. The organization of the rest of this paper is as follows: in section 2 high penetration levels of PV energy and its consequences will be discussed. In section 3 equipment models used in this research are presented. The control methods will be discussed in section 4 . In section 5 the simulation results and discussions are presented and finally conclusions close the paper.

\section{High Penetration PV and overvoltage issue}

Voltage regulation is an important subject in electrical distribution engineering, because it is the utility's responsibility to keep the customers' service voltage (the voltage at the customer's meter, or the load side of the point of common coupling (PCC)) within the acceptable range. ANSI C84.1 specifies a guideline for this range, but the utilities have the freedom to specify it differently based on their specific circumstances. ANSI C84.1 also specifies utilization voltage, which refers to the voltage at the point of use where the outlet equipment is plugged in. Furthermore, two ranges are defined, Range $A$ is recommended for normal operating conditions, while Range B corresponds to unusual conditions, so the occurrence has to be limited in time duration and frequency. Recommended service and utilization voltage limits according to ANSI C84.1 are shown in Table 1. Utilities are generally concerned with maintaining the service voltage within acceptable limits; the utilization voltage then follows automatically, provided that the house wiring is done according to building codes.

Table 1. ANSI C84.1 voltage range

\begin{tabular}{ccccc}
\hline & \multicolumn{2}{c}{ Service } & \multicolumn{2}{c}{ Utilization } \\
& Min & Max & Min & Max \\
\hline Range A (normal) & $-5 \%$ & $+5 \%$ & $-8.3 \%$ & $+4.2 \%$ \\
Range B (emergency) & $-8.3 \%$ & $+5.8 \%$ & $-11.7 \%$ & $+5.8 \%$ \\
\hline
\end{tabular}

TELKOMNIKA Vol. 15, No. 2, August 2015: $217-228$ 
By connecting a high penetration PV power plant to a distribution feeder, the voltage regulation decreases and consequently voltage rises in the PCC. Irrespective of actual adopted voltage limits (byANSI C84.1 or by individual utility), most utilities control theservice voltage indirectly, by controlling the voltage on theprimary circuit, the feeder. Service voltage is directlydependent on feeder voltage; when considered on the samevoltage base, service voltage is equal to the feeder voltageminus the voltage drop across the service transformer andsecondary circuit connection. Figure 1 shows an example ofvoltage limits for primary circuit, service entrance, andutilization based on one utility's guidelines [10]. It reflects theadjustment for assumptions about additional voltage drop inthe secondary circuit and allows for the necessary margin. Inthis study, the primary voltage and service entrance voltagelimits shown in Figure 1 were used as target limits.

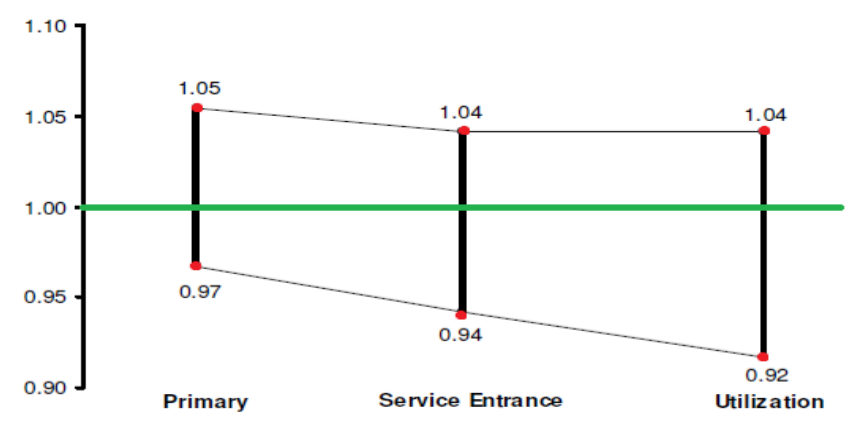

Figure 1. Voltage limits in distribution networks according to [10]

The voltage regulation practice on distribution systems is based on radial power flow from the substation to the load. Voltage drop on the feeder is a consequence of current flow, and impedance (resistance and reactance) of the feeder conductor, transformer and load. Loads require active and reactive power, and the related current that supplies the active and reactive power causes the voltage drop on feeder conductors. Feeder conductors are a given (they are selected first based on economic considerations). With conductor sizes known (their circuit parameters fixed), there are two fundamental ways to control the voltage on the feeder, by using OLTC transformers, or by installing fixed or switched capacitors to offset the reactive power demand from the load and thus reduce the current flow through the feeder and the related voltage drop. OLTC, or voltage regulator, is an essential part of distribution networks. It is typically constructed as autotransformers with automatically adjusting taps. The controls measure the voltage and load current, estimate the voltage at the remote (controlled voltage) point, and trigger the tap change when the estimated voltage is out of bounds. Multiple tap change actions may be performed until the voltage is brought within bounds. The taps typically provide a range of $\pm 10 \%$ of transformer rated voltage with 32 steps. Each step of voltage is therefore $0.625 \%$ of rated voltage. When connected to distribution systems, capacitor banks supply reactive power to offset that of the load, and consequently reduce the amount that needs to come from the substation and the associated voltage drop. The capacitor banks can be fixed (permanently connected) or switched (connected when needed), so that their supplied reactive power matches the need of the load. In practical installations this matching is seldom perfect, because the load and its reactive power demand vary continuously while the capacitor banks are switched in discrete increments. Moreover, the reactive power from capacitors varies with voltage squared and so drops off at low voltages when it is most needed. Overcompensation of the feeder (associated with too much capacitance) leads to voltage rise on the feeder and it might require action of the voltage regulator in the substation - it would lower the voltage to accommodate the rise due to overcompensation by the capacitors. Controls used for switching capacitor banks can be based on: time clock (load is correlated with time of day), temperature (heavy load such as air-conditioning is correlated with ambient temperature), voltage (low feeder voltage is an indication of the heavy load), reactive power flow (to balance the reactive 
power actually drawn by the load), or feeder current (similar to reactive power control but less expensive to implement) [11].

Since in most of developing countries, OLTC are used only in sub transmission and all distribution tap changing transformers are off-load tap changing transformers and even if OLTC is used in distribution networks, action of it has few to several seconds if not minutes delay, the maximum allowable penetration level to prevent overvoltage iscrucial.

\section{PV and Inverter Model}

\subsection{PV Model}

Figure (2) shows the equivalent circuit of a solar panel. A solar panel is composed of several photovoltaic cells that have series or parallel or series-parallel external connections. Equation (1) shows V-I characteristic of a solar panel [12].

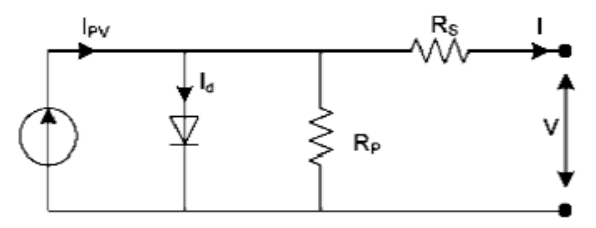

Figure 2. Equivalent circuit of Solar Panel

$$
I=I_{p v}-I_{o}\left[\exp \left(\frac{V+R_{S} I}{a V_{t}}\right)-1\right]-\frac{V+R_{S} I}{R_{p}}
$$

Where $I_{p v}$ is the photovoltaic current, $I_{0}$ is saturated reverse current, ' $a$ ' is the ideal diode constant, $V_{t}={ }^{N_{s} K T} / q$ is the thermal voltage, $\mathrm{N}_{\mathrm{s}}$ is the number of series cells, $\mathrm{q}$ is the electron charge , $\mathrm{K}$ is the Boltzmann constant, $T$ is the temperature of $p-n$ junction, $R_{S}$ and $R_{p}$ are series and parallel equivalent resistance of the solar panels. $I_{p v}$ has a linear relation with light intensity and also varies with temperature variations. $\mathrm{I}_{0}$ is dependent on temperature variations. Values of $\mathrm{I}_{\mathrm{pv}}$ and $\mathrm{I}_{\mathrm{o}}$ are calculated according to the following equations:

$$
\begin{aligned}
& I_{p v}=\left(I_{p v, n}+K_{I} \Delta T\right) \frac{G}{G_{n}} \\
& I_{o}=\frac{I_{s c, n}+K_{I} \Delta T}{\exp \left(V_{o c, n}+K_{V} \Delta T\right) / a V_{t}-1}
\end{aligned}
$$

In which $\mathrm{I}_{\mathrm{pv}, \mathrm{n}}, \mathrm{I}_{\mathrm{sc}, \mathrm{n}}$ and $\mathrm{V}_{\mathrm{oc}, \mathrm{n}}$ are photovoltaic current, short circuit current and open circuit voltage in standard conditions $\left(T_{n}=25 C\right.$ and $\left.G_{n}=1000 \mathrm{~W} / \mathrm{m}^{\wedge} 2\right)$ respectively. $K_{l}$ is the coefficient of short-circuit current to temperature, $\Delta T=T-T_{n}$ is the temperature deviation from standard temperature, $G$ is the light intensity and $K_{V}$ is the ratio coefficient of open circuit voltage to temperature.

Open circuit voltage, short circuit current and voltage - current corresponding to the maximum power are three important points of I-V characteristic of Solar Panel. These points are changed by variations of atmospheric conditions. Using Equation (4) and (5) which are derived from PV model equations, short circuit current and open circuit voltage can be calculated in different atmospheric conditions.

$$
I_{s c}=\left(I_{s c, n}+K_{I} \Delta T\right) \frac{G}{G_{n}}
$$




$$
V_{o c}=V_{o c, n}+K_{V} \Delta T
$$

\subsection{Hysteresis Current Control (HCC) of Power Electronic Unit}

Hysteresis control presents an alternative method for producing a sinusoidal ac current waveform from a dc voltage source. With this method, the controller maintains an output current that stays within a given tolerance of the reference waveform. The tolerance that the output stays within is called the "hysteresis band". Unlike the PWM switching technique, the method of hysteresis control depends on feedback from the output current to control the inverter system. The closed-loop control method enables the inverter with hysteresis control to adapt instantly to changes in the output loading.

The concept of hysteresis control can be applied to a wide range of inverter configurations and topologies. Both single-phase and three-phase inverters can be controlled by the hysteresis method as well. A common topology for single-phase inverters is the $\mathrm{H}$-bridge because it offers more controllability than the half-bridge type. It allows the use of three output states instead of two and requires half of the dc bus voltage to produce the same peak output voltage [13]. Figure 3 illustrates the fundamental concept of operation for the hysteresiscontrolled inverter.

The reference current, $I_{\text {ref }}$, represents the desired waveform for the output load current. The top and bottom hysteresis limits form the hysteresis band, which corresponds to the tolerance limit of the inverter controller.

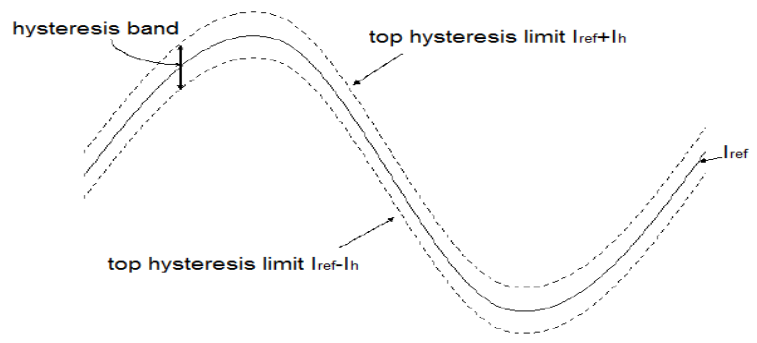

Figure 3. Concept of hysteresis band and hysteresis controller

The two-level inverter controller will apply the positive or negative dc bus voltage to the load in order to keep the output current within the hysteresis band. For example, when the output current rises above the top hysteresis limit, the inverter controller will respond by switching the transistors to apply the negative dc bus voltage to the load and effectively reduce the value of the output current to bring it below the top hysteresis limit. The inverter controller will keep the negative dc bus voltage across the load until the output current reaches the bottom hysteresis limit. After the output current drops below the bottom limit, the inverter controller will send the appropriate gating signals to the transistors to switch them to apply the positive dc bus voltage across the load. This will bring the output current back up above the bottom hysteresis limit and within the allowable tolerance band around the reference waveform. The controller will continuously repeat this cycle to maintain the output load current within the hysteresis band.

Unlike other high-fidelity inverter control strategies, the hysteresis controller will operate at a variable switching frequency that is spread across the spectrum. The instantaneous switching frequency $f_{s}$ at any point on the current waveform can be predicted by [14]:

$$
f_{s}=\frac{\left(V_{D C}-\left|I_{r e f}\right|\right)\left|I_{r e f}\right|}{L h V_{D C}}
$$

Where $V_{D C}$ is the dc bus voltage, $I_{\text {ref }}$ is the instantaneous voltage of reference current signal, $\mathrm{L}$ is the load inductance, and $h$ is the width of the hysteresis band. As reflected in Equation (6), the hysteresis inverter will switch faster at points in the cycle where the reference current reaches its maximum and minimum values and switch much slower when $I_{r e f}$ is close to zero in magnitude. A larger load inductance will allow the inverter to switch at a lower frequency to 
maintain the current within the same hysteresis band. Since $f_{s}$ will diverge to infinity if $L$ is equal to zero, there must be some inductance present in the load for the hysteresis-controlled inverter to work. The switching frequency is also inversely proportional to $h$. The inverter will switch at higher rates overall to achieve a higher fidelity output current within a smaller hysteresis band.

Figure 4 shows a HCC for a single phase VSI. Assume the VSI terminal voltage V connects to a sinusoidal voltage source e through an equivalent inductance $L$ and resistance $R$. If we want to control output current $i$ to track a certain reference current $i^{*}$, according to Fig. 4-a we have instantaneous value equation as:

$$
L \frac{d i}{d t}+R i=V-e
$$

When the SOFC output current is equal to reference current $i^{*}$, the corresponding equation will be:

$$
L \frac{d i^{*}}{d t}+R i^{*}=V^{*}-e
$$

Where $\mathrm{V}^{*}$ is the reference VSI terminal voltage corresponding to $\mathrm{i}^{*}$. If we define current tracking error $\Delta \mathrm{i}=\mathrm{i}-\mathrm{i}^{*}$, it is clear that when $\mathrm{R}=0$, we have:

$$
L \frac{d \Delta i}{d t}=V-V^{*}
$$

Where VSI terminal voltage $\mathrm{V}$ is:

$$
V=\left\{\begin{array}{cc}
\frac{E}{2} & (s=1) \\
-\frac{E}{2} & (s=0)
\end{array}\right.
$$

Where $\mathrm{E}$ is the VSI $\mathrm{dc}$ voltage and $\mathrm{s}$ the solid-state switch status. When $\Delta \mathrm{i}$ is greater than zero and beyond the tolerance, $\mathrm{s}$ is controlled to be at lower level $\mathrm{s}=0$ and therefore $\left(\mathrm{V}-\mathrm{V}^{*}\right)<0$ (note the dc voltage should be big enough for effective current tracking) which makes $\Delta \mathrm{i}$ to reduce. In the same way if $\Delta \mathrm{i}<0$ and beyond the tolerance, $\mathrm{s}$ is controlled to be at higher-level $\mathrm{s}=1$ and therefore $\left(\mathrm{V}-\mathrm{V}^{*}\right)>0$ which makes $\Delta \mathrm{i}$ to increase. The corresponding hysteresis current control block diagram is shown in Figure 4.

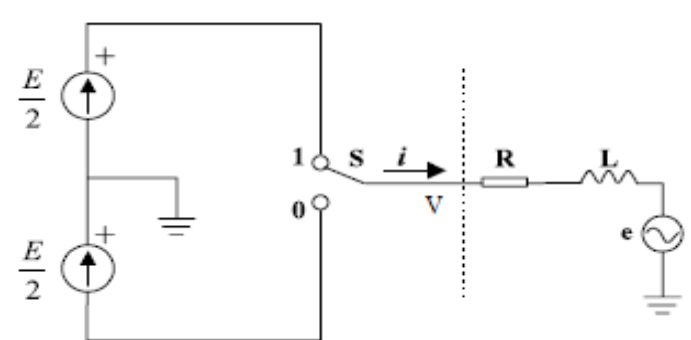

(a)

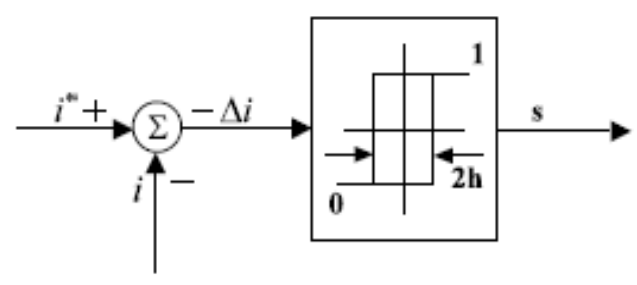

(b)

Figure 4. single phase VSI and HCC

\section{Control and Coordination Scheme}

\subsection{MPPT Algorithm}

In [15] a simple hybrid method has been proposed for MPPT of solar arrays. This algorithm consists of two stages; the first one is to estimate the voltage of maximum power point $\left(\mathrm{V}_{\mathrm{MPP}}\right)$ and the second is to track the exact maximum power point using the classic Perturbation and Observation (P\&O) with a small amplitude and frequency of perturbations. In the first stage, $\mathrm{V}_{\mathrm{MPP}}$ is calculated using Equation (5) which is a linear equation in terms of temperature. Using that method, there is no need to disconnect the solar panel in order to measure the open circuit 
voltage. This method has lower power oscillations and higher efficiency also better tracking performance in rapid changes of light intensity and temperature.

In this section, an improved hybrid method for MPPT will be proposed. In this method instead of calculating $V_{\text {MPP }}$, the current of the maximum power point $\left(I_{M P P}\right)$ is calculated. This leads to an improved efficiency and higher accuracy [16]. The overall algorithm of the improved hybrid MPPT method has been shown in Figure 5. The relation between output current and voltage of PV array has been shown in Equation (1). In this equation, three parameters of 'a', $R_{S}$ and $R_{P}$ are not given by the manufacturer. In datasheet of a given PV array there is usually three pints of V-I characteristics given by the manufacturer which are short circuit current, open circuit voltage and voltage and current of maximum power point in standard atmospheric condition of $1000 \mathrm{w} / \mathrm{m}^{2}$ and $25^{\circ} \mathrm{C}$. By substituting these three points in Equation (12) and solving set of equations of (1) three parameters of ' $a$ ', $R_{S}$ and $R_{P}$ will be determined.

$$
\left\{\begin{array}{c}
I_{S C, n}=I_{P V, n}-I_{O, n}\left(\exp \left(\frac{I_{S C, n} R_{S}}{a V_{T, n}}\right)-1\right)-\frac{I_{S C, n} R_{S}}{R_{P}} \\
0=I_{P V, n}-I_{O, n}\left(\exp \left(\frac{V_{O C, n}}{a V_{T, n}}\right)-1\right)-\frac{V_{O C, n}}{R_{P}} \rightarrow a, R_{S}, R_{P} \\
I_{M P P, n}=I_{P V, n}-I_{O, n}\left(\exp \left(\frac{I_{M P P, n} R_{S}}{a V_{T, n}}\right)-1\right)-\frac{I_{M P P, n} R_{S}}{R_{P}}
\end{array}\right.
$$

To estimate the maximum power point current in each atmospheric condition we need the short circuit current in that atmospheric condition. In previous methods, the measurement was done by disconnecting the load actually short circuiting the terminals of the panel. In this proposed MPPT method, the short circuit current will be calculated using mathematical equations and measurement of output voltage and current of PV. The instantaneous values of voltage, current and temperature of the solar panel are measured and $I_{P V}$ in which is the only variable dependent on light intensity in and also to temperature will be calculated using Equation (12). In this equation, $\mathrm{V}_{\mathrm{T}}$ and $\mathrm{I}_{\mathrm{O}}$ which are temperature dependent are updated using $V_{t}=N_{S} K T / q$ and Equation (3).

$$
I_{P V}=I+I_{O}\left(\exp \left(\frac{V+I R_{S}}{a V_{T}}\right)-1\right)+\frac{V+I R_{S}}{R_{P}}
$$

Knowing $I_{P V}$, the nonlinear Equation (12) will be solved iteratively to calculate $I_{S C}$. This iterative equation will be repeated $\mathrm{m}$ times and in each iteration, $\mathrm{I}_{\mathrm{SC}}$ of the previous iteration will be substituted (Equation (13)). After $\mathrm{m}$ iteration $\mathrm{I}_{\mathrm{sc}}$ no longer varies which is indicative of convergence of the short circuit current. ' $\mathrm{m}$ ' is a small integer because $I_{\mathrm{PV}}$, which is the first estimation of $I_{\mathrm{SC}}$, is very close to it. In other words in a few iterations $I_{\mathrm{SC}}$ will be found with an acceptable approximation.

$$
\begin{aligned}
& I_{S C, 1}=I_{P V} \\
& I_{S C, m+1}=I_{P V}-I_{O}\left(\exp \left(\frac{I_{S C, m} R_{S}}{a V_{T}}\right)-1\right)-\frac{I_{S C, m} R_{S}}{R_{P}} \\
& m=1,2, \ldots m \quad, \quad I_{S C}=I_{S C, m+1}
\end{aligned}
$$

In the proposed method, the fine tuning loop is used to correct the calculation of the $I_{\mathrm{SC}}$ to compensate the effect of the measurement error and possible model mismatch of solar panel. In this method, In case of small variations of temperature and $I_{P V}$, the fine tuning loop regulates output power. Since $I_{P V}$ varies with radiation intensity, it can be inferred that the fine tuning loop will be run when atmospheric conditions are approximately constant. Consequently because in rapid changes of atmospheric conditions the fine tuning loop is not run, the amplitude of the perturbations of the P\&O algorithm does not need to be great which will in turn will result in small variations of power in steady state conditions around the optimal value. 


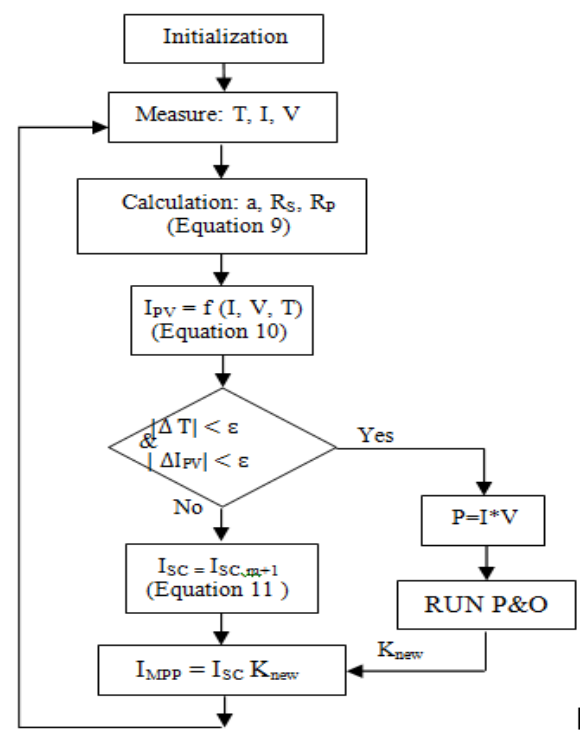

Figure 5. The flowchart of the proposed MPPT method

\subsection{Link Voltage Control}

The overall algorithm of the DC link voltage control strategy has been shown in fig (6). This algorithm consists of two main modes. One mode is when the PV generates power $\left(P_{P V}>P_{\min }\right)$.This power will be delivered to the network through the Hysteresis Controlled Inverter. The other mode is when the power generated by the PV is less than the threshold $P_{\text {min. }}$. In both modes, $V_{D C}$ must be greater than $V_{\text {min }}$ in order to have a satisfactory operation of the inverter.

In the first mode, the generated power of the $\mathrm{PV}$ is delivered to the $\mathrm{DC}$ link through a boost converter. When $V_{D C}$ is less than the threshold $\left(V_{D C-m i n}\right)$, according to the control strategy the power of the PV is fed to the DC link to maintain in acceptable range. In this situation, the power delivered to $\mathrm{P}_{\mathrm{g}}$ is zero, in other words the power of the $\mathrm{PV}$ is solely dedicated to charge the capacitor of the $D C$ link. In a situation where $V_{D C}$ is greater than $V_{D C-m i n}$ a portion of the $P_{P V}$ is used to charge the capacitor and the rest will be delivered to the grid through the inverter. When $V_{D C}$ reaches maximum allowable voltage $V_{D C \text {-max }}$, the power of the $P V$ is all fed to the grid. When $V_{D C}$ is between $V_{D C \text {-min }}$ and $V_{D C-m a x}$ there is a linear relationship between the power used to charge the capacitor and the $\mathrm{V}_{\mathrm{DC} \text {-max }}-\mathrm{V}_{\mathrm{DC}}$.

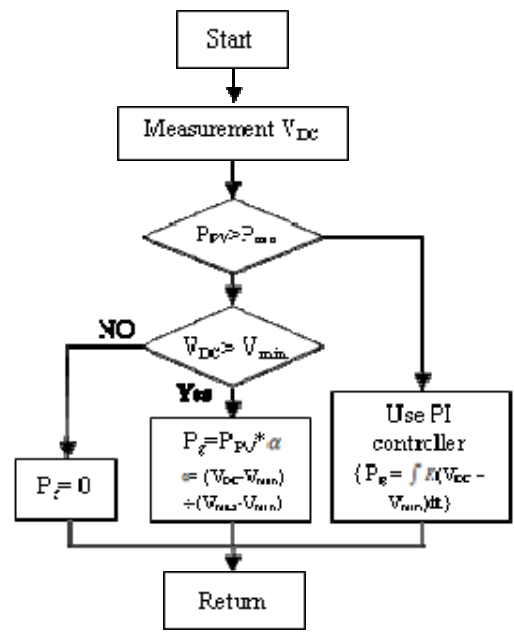

Figure 6. The overal algorithm of the DC link voltage control 


\subsection{Safe Operation Zone (SOZ)}

In this paper, we assume that the nominal voltage of the distribution network is the voltage which is measured in zero penetration level. Any higher voltage is overvoltage and any lower voltage is undervoltage. The microgrid in this research comprises of a PV power plant with boost converter and hysteresiscurrent controlled inverter and a DC link and also a constant load. This microgrid is connected to the grid via an On-load Tap Changing transformer (OLTC).

The traditional distribution system has been designed as a unidirectional power flow network. As more and more distributed renewable sources are connected to the grid, the original unidirectional network will be changed toward the bidirectional network in the future. This change brings utility operation issues such as the voltage rise problem caused by the reverse power flow from the distributed renewable energy generation. Figure 7 illustratesthe one line diagram of the simplified distribution network. There is a distributed generator connected to the load side. The generator voltage $V_{G}$ can be approximately expressed in:

$$
V_{G} \approx V_{2}+R\left(P_{G}-P_{L}\right)+X\left(Q_{G}-Q_{L}\right)
$$

Where $V_{2}$ is the substation secondary bus voltage, $X$ is the feeder line reactance and $R$ is feeder line resistance. $P_{G}$ and $Q_{G}$ are the real and reactive power provided by the generator, respectively. $P_{L}$ and $Q_{L}$ are the real and reactive power consumed by the load.

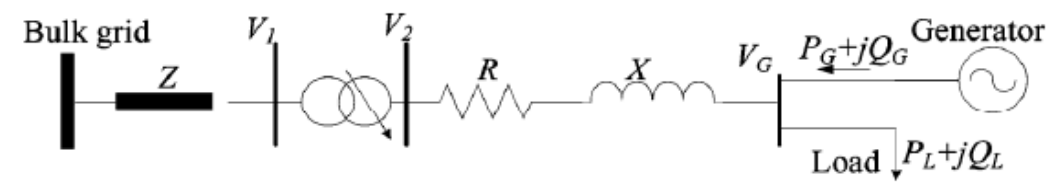

Figure 7. One line diagram of a typical grid connected DG

Equation (14) shows that the generator voltage may be higher than the upper-limit if the network $X / R$ ratio is relatively low and there is a significant reverse power flow. One solution is that the generators can absorb a relatively large reactive power to compensate the reverse power flow. The alternative solution is that the substation secondary voltage can be correspondingly controlled or the real power injection to the grid can be decreased.

Currently, standards such as IEEE 1547 and UL1741 state that the PV inverter "shall not actively regulate the voltage at the PCC." Therefore, PV systems are designed to operate at unity power factor (i.e., provide only active power) because this condition will produce the most real power and energy. This limitation is a matter of agreement instead of a technical one; many inverters have the capability of providing reactive power to the grid in addition to the active power generated by their PV cells. The amount of reactive power $(Q)$ available from the inverter depends on its ratings $(S)$ and the active power (Ppv) supplied by the PV array. Consequently, the inverter can use its entire rating to supply $Q$ if $P p v$ equals zero (there is no sun), and at the other extreme, it has no $Q$ capability if $P p v$ equals $S$. Some $Q$ capability can always be retained by over-sizing the inverter. In addition to the continuous reactive power support, inverters can operate very fast (milliseconds to microseconds with high switching frequency inverters) compared to capacitors, which can cause switching transients.

In this paper, a safe operation zone (SOZ) will be determined according to the load, impedance of grid and transformers. SOZ is the zone in which according to nominal irradiance and temperature conditions of a certain geographic site, load level and grid characteristics, the devised penetration level would not cause over voltages above the ANSI standards.

\section{Simulation and Discussions \\ 5.1. System Description}

The model of PV array has been presented in section 3. The PV array is connected to the inverter via a boost converter. A capacitor is connected to the output of the boost converter to provide transient energy storage capability. A hysteresis controlled inverter connects DC link to the PCC via a RL filter. Distribution network lines are simulated as RL impedances which 
connect grid voltage source to the OLTC. A schematic of the overall power systems is shown in Figure 8.

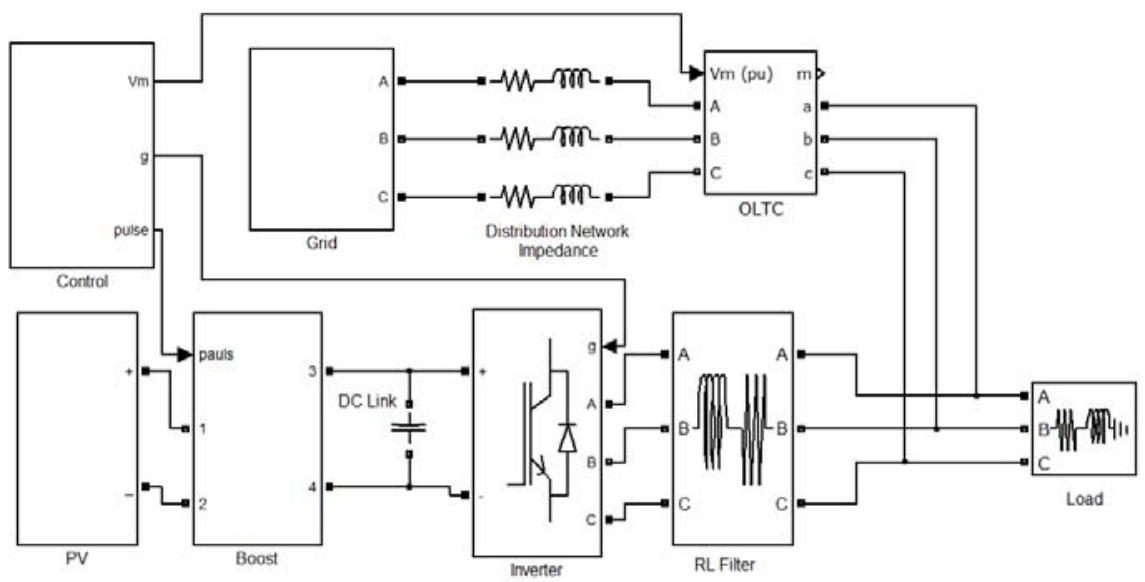

Figure 8. The block diagram of the grid connected photovoltaic power plant with high penetration level

\subsection{Simulation Results}

Different levels of penetration for the grid-connected power plant have been simulated. Figure 9 shows grid, PV and load power in kilo watts for $100 \mathrm{kw}$ nominal load. In Figure 9(a) the PV Penetration Level (PL) is $10.2 \%$ and PV generates $10.5 \mathrm{kw}$. The voltage of point of common coupling is 385.3 in which has $1.3 \%$ overvoltage. In Figure 9 (b) the penetration level of PV has been increased to $21 \%$. The voltage of PCC is 391.3 volts which is $2.9 \%$ higher than the nominal voltage of $380 \mathrm{v}$ but it is in the permitted range according to grid standards. The penetration level in Figure 9(c) is $42 \%$ and voltage of PCC is 403 volts. The overvoltage in this $\mathrm{PL}$ is $6 \%$ which is unacceptable. As can be seen, in higher penetration levels, the amount of load is also higher since the effective voltage on load terminals is higher. Figure 10 shows the same simulation for $70 \mathrm{kw}$ loading. As can be seen, in lower loadings, (here $70 \mathrm{kw}$ ) the maximum allowable penetration level increases. Figure 11 shows this in greater details.
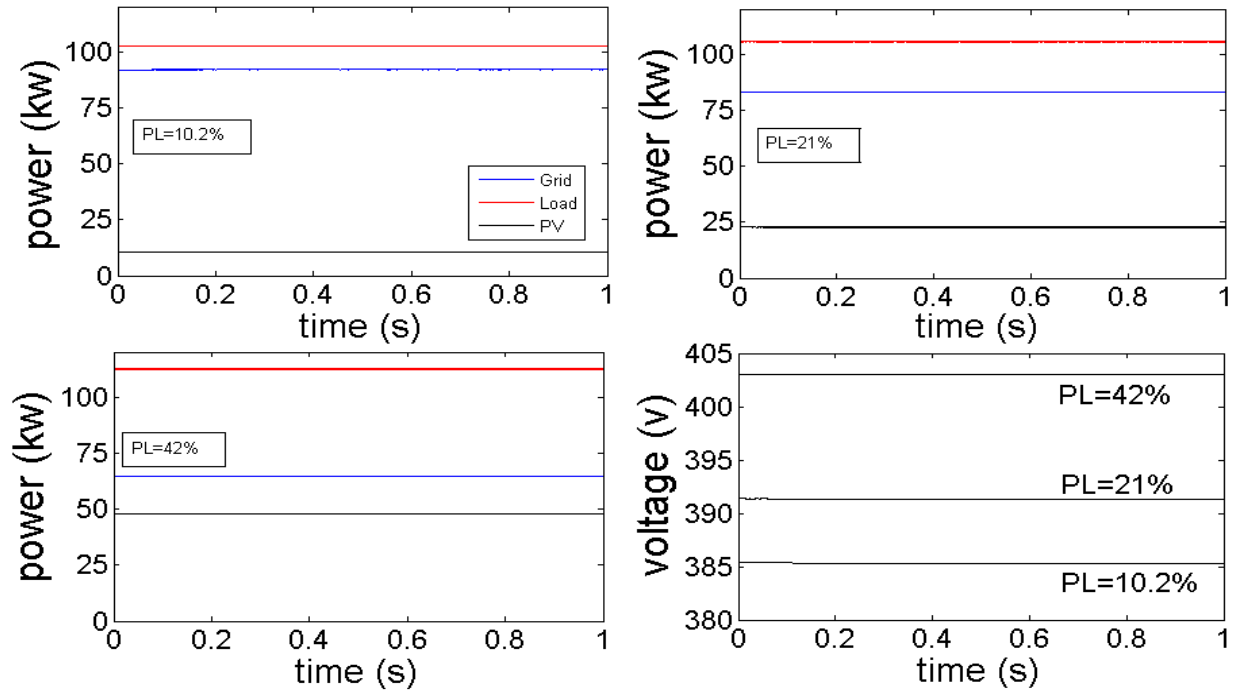

Figure 9. Grid, load and PV powers for different penetration levels and their corresponding voltages of PCC with nominal loading of $100 \mathrm{kw}$ 

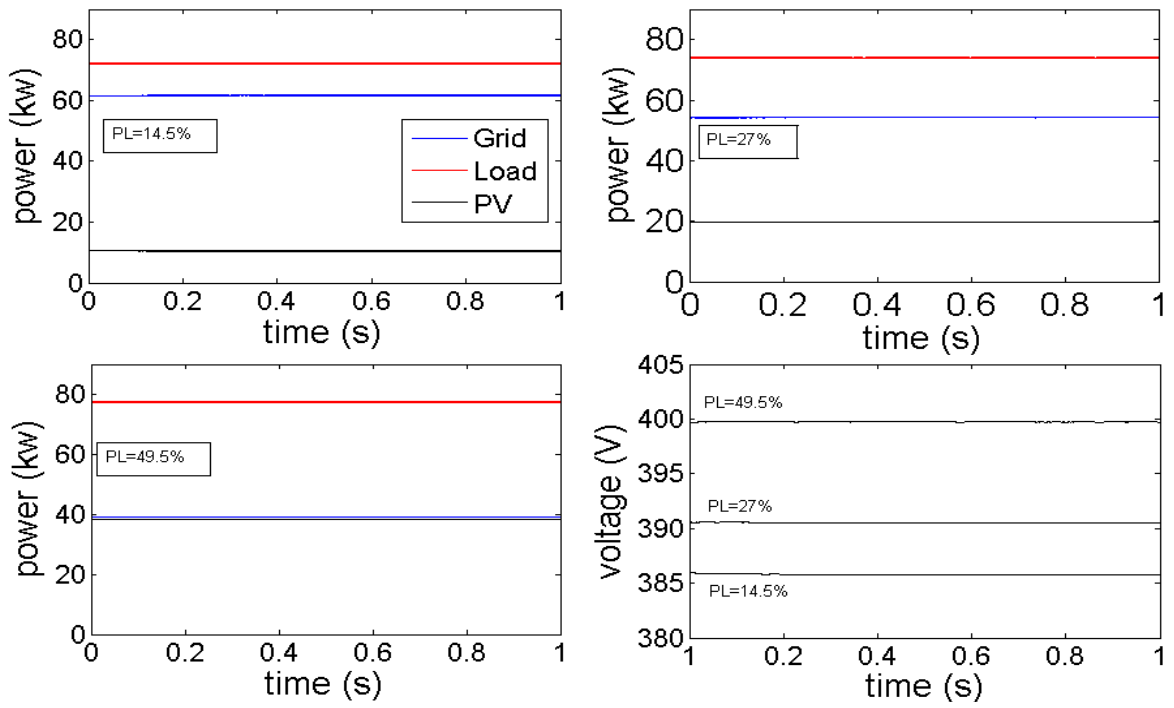

Figure 10. Grid, load and PV powers for different penetration levels and their corresponding voltages of PCC with nominal loading of $70 \mathrm{kw}$

Figure 11 shows the voltage of the grid at the PCC as a function of penetration level for three different loadings. As can be seen, as the penetration level increases, the voltage of common coupling also raises. The maximum acceptable voltage in this microgrid is $395 \mathrm{v}$ and consequently the maximum penetration level for $100 \mathrm{kw}$ loading in this microgrid is $28 \%$. For $70 \mathrm{kw}$ and $50 \mathrm{kw}$ loading, maximum penetration levels are $38 \%$ and $53 \%$ respectively.

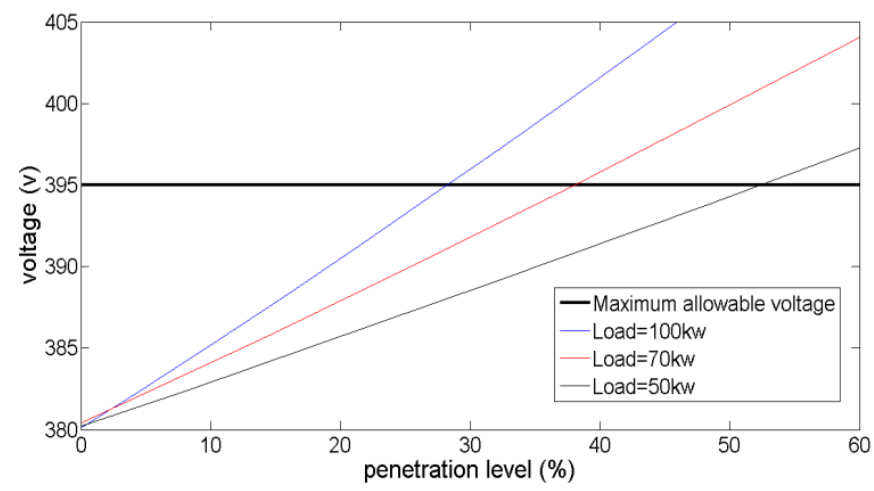

Figure 11. Voltage of the grid at the point of common coupling as a function of penetration level.

The amount of penetration level could be more if the OLTC is set accordingly. For example if desired maximum penetration level is $60 \%$ the output voltage of OLTC should be set so that in normal operation of the microgrid (nominal load and PV penetration) the voltage of PCC remains in allowed range. Since the amount of power generated by PV is a function of solar irradiance and it is not constant throughout the day, the output voltage of OLTC should be designed for maximum expected solar irradiance (maximum expected penetration level). In this situation, the limiting factor would not be the overvoltage problem but other issues will rise in PV microgrid designed to mitigate over voltages due to high penetration PV. Issues like cloud passage, load change and THD rate could also limit the penetration level. 


\section{Conclusion}

In this paper a power control scheme for a high penetration photovoltaic power plant in a radial distribution network was be presented. This control scheme includes an efficient Maximum Power Point Tracking (MPPT), DC link voltage control by managing power balance between the hysteresis controlled inverter and a boost converter. Another aspect of High Penetration PV (HPPV) which is overvoltage in Point of Common Coupling (PCC) was also investigated and maximum allowable Penetration Level $(\mathrm{PL})$ will be determined. Simulations have been done in Matlab/Simulink environment. A safe operation zone for PV power plant was determined in which according to maximum output power of the PV power plant in specific geographical site the maximum allowable penetration level was found.

\section{References}

[1] J Maire, D Von Dollen. Profiling and mapping of intelligent gridR\&D programs. IEEE Working Group on Distribution Automation. 2006.

[2] Available: http://www.oe.energy.gov/DocumentsandMedia/SG_MYPP.pdf

[3] CL Masters. Voltage rise: The big issue when connecting embedded generation to long $11 \mathrm{kV}$ overhead lines. Inst. Elect. Eng. Power Eng. Journal. 2002; 16(1): 5-12.

[4] P Carvalho, P Correia, L Ferreira. Distributed reactive powergeneration control for voltage risemitigation in distribution networks. IEEE Trans. Power Syst. 2008; 23(2): 766-772.

[5] DG power quality, protection, and reliabilitycase studies report. General Electric Corporate R\&D. NREL report NREL/SR-560-34635. 2003.

[6] Report on distributed generation penetration study. NREL report NREL/SR-560-34715. 2003.

[7] M Hojo, H Hatano, Y Huwa. Voltage rise suppression by reactive power control with cooperating photovoltaic generation systems. In Proc. 20th CIRED Int. Conf. Electr. Distrib. 2009: 1-4.

[8] E Liu, J Bebic. Distribution system voltage performance analysis for high-penetration PV. 2008 Available: http://www1.eere.energy.gov/solar/pdfs/42298.pdf, NREL/SR-581-42298.

[9] Rob McMonagle. The Potential of Solar PV in Ontario. The Canadian Solar Industries Association. 2006

[10] H. Lee Willis. Power Distribution Planning Reference Book. CRC Press. 2004.

[11] Electric Power Distribution Handbook", Tom Short, CRC Press, 2003.

[12] MG Villalva, JR Gazoli, ER Filho. Comprehensive approach to modeling and simulation of photovoltaic arrays. IEEE Trans. Power Electron. 2009; 24(5): 1198-1208.

[13] Ned Mohan, Tore M Undeland, William P Robbins. Power Electronics. 3rd Edition. Hoboken, New Jersey: John Wiley and Sons, Inc. 2003.

[14] Allie Auld, Fabian Muelle, Keyue Ma Smedley, Scott Samuelsen, Jack Brouwer. Applications of onecycle control to improve the interconnection of a solid oxide fuel cell and electric power system with a dynamic load. Journal of Power Sources 179. 2008: 155-163.

[15] MH Moradi, AR Reisi. A hybrid maximum power point tracking method for photovoltaic systems. Solar Energy 85. 2011: 2965-2976.

[16] T Noguchi, S Togashi, R Nakamoto. Short-current pulse-based maximum-power-point tracking method for multiple photovoltaic-and-converter module system. IEEE Trans Ind Electron. 2002; 49(1): 217- 223. 